Hiroaki Kayahara $\cdot$ Hidehisa Yamagata $\cdot$ Hiroaki Tanioka Tetsuro Miki • Hiroyuki Hamakawa

\title{
Frequent loss of heterozygosity at 3p25-p26 is associated with invasive oral squamous cell carcinoma
}

\begin{abstract}
Recent molecular evidence suggests that allelic deletions of chromosomes are involved in the carcinogenesis of various neoplasms, including oral squamous cell carcinoma (OSCC). To determine the role of $3 p$ deletions in Japanese OSCC and to define the localization of putative tumor suppressor genes, we initially examined loss of heterozygosity $(\mathrm{LOH})$, using nine microsatellite markers in 36 OSCCs and 28 oral epithelial dysplastic lesions (OEDLs). $\mathrm{LOH}$ on chromosome $3 \mathrm{p}$ was observed at one or more loci in $72 \%$ of OSCCs and $18 \%$ of OEDLs. Fourteen $(61 \%)$ of 23 OSCC patients informative at D3S2450 (3pter-p24.2) showed LOH most frequently, in contrast to OEDL, where $\mathrm{LOH}$ was never seen at this locus. Interestingly, we found a significant association between an allelic deletion at this locus and the histologic grade of mode of tumor invasion. Therefore, we also examined allelic deletion on chromosome 3p telomeric to where D3S2450 was located. A common deletion region was identified between D3S2450 and D3S3591. Our results provide evidence for the presence of a tumor suppressor gene in a $0.8-\mathrm{cM}$ region bordered by D3S2450 and D3S3591 at 3p25-p26, which may play a role in carcinogenesis and invasion of OSCC.
\end{abstract}

Key words Loss of heterozygosity - Microsatellite instability - Oral squamous cell carcinoma - Oral epithelial dysplastic lesion $\cdot$ Chromosome $3 p$

H. Kayahara $(\bowtie) \cdot H$. Tanioka $\cdot$ H. Hamakawa

Department of Oral and Maxillofacial Surgery, Ehime University

School of Medicine, Shitsukawa, Shigenobu-cho, Onsen-gun, Ehime 791-0295, Japan

Tel. +81-89-960-5393; Fax +81-89-960-5396

e-mail: kayahara@m.ehime-u.ac.jp

H. Yamagata $\cdot$ T. Miki

Department of Geriatric Medicine, Ehime University School of

Medicine, Ehime, Japan

\section{Introduction}

An estimated 5500 new cases of oral cancer are expected to be diagnosed each year in Japan, with $80 \%$ of these histologically designated as squamous cell carcinoma; approximately 2500 people will die of oral cancer. More than $80 \%$ of oral cancers occur in patients over the age of 50 years. The incidence increases steadily with age until age 70 years, when the rate levels off. The primary risk factors for oral cancer in Japanese men and women are tobacco and alcohol use. Although easily detected and often cured in its early stage, the prognosis of the advanced stage is poor. Most patients, after multidisciplinary treatment, suffer from severe cosmetic and/or functional difficulties.

Among genetic changes, loss of heterozygosity $(\mathrm{LOH})$ is a frequent mechanism of inactivation of tumor suppressor genes where one allele is already altered. Frequent allelic deletion at specific loci in both hereditary and sporadic tumors may indicate the location of a putative tumor suppressor gene (Ponder 1988). For determination of the location of some putative tumor suppressor genes, various studies have been carried out, using polymorphic markers. To date, in head and neck cancer, including oral squamous cell carcinoma (OSCC), LOH has frequently been identified on chromosomes 2q, 4q, 7q, 8p, 9p, 10q, 11q, 13q, 14q, 17p, 18q, and 22q (Uzawa et al. 1996; Jares et al. 1997; Matsuura et al. 1998; Pearlstein et al. 1998; El-Naggar et al. 1998; Ransom et al. 1998; Ogawara et al. 1998; Mutirangura et al. 1998; Miyakawa et al. 1998; Wang et al. 1999; Gasparotto et al. 1999; Califano et al. 1999). Other studies have also reported a high frequency of deletion at chromosome $3 p$ in diverse neoplasms, as well as in oral cancer (Fullwood et al. 1999; Chino et al. 1999). Investigation of the $3 p$ locus in head and neck cancer, including oral cancer, has shown a relatively high incidence of $\mathrm{LOH}$, ranging from $58 \%$ to $81 \%$ (Ishwad et al. 1996; Partridge et al. 1994). These findings suggest that the chromosome $3 p$ locus may contain a tumor suppressor gene that plays a role in OSCC carcinogenesis. However, it remains unclear whether LOH in this region is of biological significance, or whether it only 
reflects a consequence of the mechanism generating the deletion of $3 p$. The existence of a putative tumor suppressor gene masked by allelic deletions is suggested by the correspondence of $\mathrm{LOH}$ with clinicopathological factors. LOH on $3 p$ was reported to correlate with poor survival in lung and oral cancer (Mitsudomi et al. 1996; Partridge et al. 1996). These findings suggest a tumor suppressor gene on $3 p$ involved in the development of several types of tumor.

Microsatellite instability (MI) is a form of genomic instability demonstrated in neoplasms in which the lengths of microsatellite DNA sequences in patients' tumors diverge from those in their normal tissue counterparts. Tumors diagnosed as hereditary nonpolyposis colorectal cancer show MI at many tested microsatellite loci. However, sporadic carcinomas, in general, display quantitatively less MI (Schmitt et al. 1999). Investigation of MI in OSCC and oral epithelial dysplastic lesions (OEDLs) has provided evidence that mismatch-repair genes are implicated in the genesis of oral cancer.

The aim of this study was to perform a preliminary assessment of genomic instability of $3 p$ in Japanese patients with OSCC, and to determine the common deletion region that may include the tumor suppressor gene. We also examined the differences in LOH between OSCC and OEDL to determine the timing of genetic changes.

\section{Patients and methods}

\section{Patient materials}

A total of 36 OSCC and 28 OEDL tissue samples were obtained by incisional or excision biopsy from Japanese patients at Ehime University Hospital from 1996 to 1998. None of the patients had received any prior radiation or chemotherapy. Heparinized peripheral blood was collected as corresponding normal tissue. OSCC was classified by tumor site, tumor size, stage, differentiation, mode of tumor invasion, and presence or absence of local lymph node metastasis (Table 1). The mode of tumor invasion was classified as low (grade 1,2) or high invasive type (grade 3, 4C, 4D) according to previously reported criteria (Yamamoto et al.1983). Tumor size and stage were classified into two types according to the criteria of the International Union Against Cancer (UICC). The OEDLs consisted of 26 cases of mild dysplasia and 2 of severe dysplasia. All patients gave informed consent before enrollment in this study.

\section{DNA preparation}

Ten 5- $\mu \mathrm{m}$ sections from formalin-fixed, paraffin-embedded specimens were used for DNA extraction from OSCC and OEDL tissues. One section was stained with hematoxylin and eosin to facilitate precise identification of neoplastic and nonneoplastic cells. After the stained sections were examined, unstained sections of the specimens were
Table 1. Clinicopathological features of OSCC and OEDL

\begin{tabular}{|c|c|}
\hline Characteristics & No. \\
\hline OSCC & (36) \\
\hline \multicolumn{2}{|l|}{ Tumor site } \\
\hline Tongue & 15 \\
\hline Lower gingiva & 9 \\
\hline Upper gingiva & 4 \\
\hline Buccal mucosa & 4 \\
\hline Maxillary sinus & 3 \\
\hline Floor of mouth & 1 \\
\hline \multicolumn{2}{|l|}{ Tumor size $^{\mathrm{a}}$} \\
\hline 1,2 & 27 \\
\hline 3,4 & 9 \\
\hline \multicolumn{2}{|l|}{ Lymph node metastasis } \\
\hline$(+)$ & 12 \\
\hline$(-)$ & 24 \\
\hline \multicolumn{2}{|l|}{ Differentiation } \\
\hline Well & 19 \\
\hline Moderate & 10 \\
\hline Poor & 7 \\
\hline \multicolumn{2}{|c|}{ Mode of tumor invasion ${ }^{\mathrm{b}}$} \\
\hline Grades 1,2 & 17 \\
\hline Grades $3,4 \mathrm{C}, 4 \mathrm{D}$ & 19 \\
\hline \multicolumn{2}{|l|}{ TNM stage $^{\mathrm{a}}$} \\
\hline I, II & 17 \\
\hline III, IV & 19 \\
\hline OEDL & (28) \\
\hline Leukoplakia & 26 \\
\hline Carcinoma in situ & 2 \\
\hline
\end{tabular}

OSCC, Oral squamous cell carcinoma; OEDL, oral epithelial dysplastic lesion

${ }^{a}$ Classified according to the criteria of the International Union Against Cancer

${ }^{\mathrm{b}}$ Classified according to the criteria of Yamanoto et al. (1983)

microdissected under a light microscope to separate the tumor areas from adjacent nonneoplastic areas. After deparaffinization, the microdissected samples were incubated in sodium dodecyl sulfate (SDS)-proteinase $\mathrm{K}$ at $50^{\circ} \mathrm{C}$ for $72 \mathrm{~h}$, with additional proteinase $\mathrm{K}$ being added every $24 \mathrm{~h}$. Digested products were purified by treatment with phenol-chloroform. DNA was precipitated by the ethanol precipitation method. Normal control DNA from peripheral blood was isolated by the standard method using phenol-chloroform extraction.

\section{Polymerase chain reaction (PCR)-LOH assay}

In this study, we used trinucleotide or tetranucleotide microsatellite markers mapped on the short arm of chromosome 3 for the mapping of putative tumor suppressor genes on 3p. These were D3S2450 (3pter-p24.2), D3S1516 (3p25p24.2), D3S1537 (3p24.2-p22), D3S2447 (3p24.2-p22), D3S2414 (3p24.2-p22), D3S2411 (3p24.2-p22), D3S2420 (3p21.3-p21.2), D3S1514 (3p21.1-p14.2), and D3S1540 (3p21.1-p14.2). Primers for PCR amplification were obtained from Research Genetics (Huntsville, AL, USA). The PCR mixture was prepared as follows: $100 \mathrm{ng}$ of sample DNA, $10 \mathrm{pmol}$ of each primer, $10 \mathrm{mM}$ Tris- $\mathrm{HCl}$ (pH8.3), $50 \mathrm{mM} \mathrm{KCl}, 1.5 \mathrm{mM} \mathrm{MgCl}_{2}, 200 \mu \mathrm{M}$ dNTPs, and 0.5 unit Taq DNA polymerase (Takara Shuzo, Kyoto, Japan) in a final volume of $20 \mu \mathrm{l}$. PCR was performed with 30 cycles of dena- 
turation at $94^{\circ} \mathrm{C}$ for $1 \mathrm{~min}$, annealing at $55-57^{\circ} \mathrm{C}$ for $1 \mathrm{~min}$, and extension at $72^{\circ} \mathrm{C}$ for" ! min. Samples were then resolved by electrophoresis on $6 \%$ polyacrylamide gel and ethidium bromide staining. Allelic reductions in the intensity of alleles between tumor and normal DNA were calculated by quantitative densitometry, utilizing National Institutes of Health (NIH) Image software, and a value greater than 0.5 was considered indicative of $\mathrm{LOH}$. MI was identified as a novel band in tumor DNA not seen in the paired normal DNA. Each PCR was performed at least twice, and was defined visually for $\mathrm{LOH}$ and MI by three independent observers.

Assessment of LOH and MI at 3pter-p24.2

As LOH at locus D3S2450 (3pter-p24.2) was associated with the mode of tumor invasion and was found most frequently in the previous preliminary assessment, we examined the 36 OSCCs to determine the common deletion region. We used dinucleotide microsatellite markers for examination by fluorescent microsatellite assay. These were: D3S1560 (3p26-p25), D3S1304 (3p26-p25), D3S3591 (3p26-p25), D3S1038 (3p26.1-p25.2), D3S1597 (3pterp24.2), D3S1293 (3pter-p24.2), and D3S2335 (3pter-p24.2). One primer of each pair was fluorescence-labeled at the $5^{\prime}$ end with 6-FAM. Fluorescent PCR was performed as well as the nonlabeled PCR described above. Fluorescent DNA products were mixed with internal standard-size markers (Tamra 500; Applied Biosystems, Tokyo, Japan) and fractionated by capillary-electrophoresis, using an ABI PRISM 310 Genetic Analyzer. The sizes of two alleles for heterozygous cases were assigned according to the two peaks of greatest height in the normal sample. The allele ratio was calculated for each paired normal and tumor sample and then the tumor ratio was divided by the normal ratio. A ratio of less than 0.5 was taken to be indicative of $\mathrm{LOH}$ to allow for up to $50 \%$ contaminating normal cells in the tumor cells (Cawkwell et al. 1994). All assays were performed at least twice to ensure that consistent results were obtained. Two point linkage analysis with these markers was performed in Centre d'Etude du Polymorphisme Humain (CEPH) pedigrees; 102, 884, 1331, 1332, 1347, 1362,1413 , and 1416.

\section{Statistical analysis}

Fisher's exact test was used for statistical analysis of the results. One-tailed $P$ values less than 0.05 were considered significant.

\section{Results}

Allelic deletion of chromosome $3 p$ in OSCC and OEDL

We analyzed matched pairs of normal/tumor DNA from 36 OSCCs and 28 OEDLs by PCR-LOH assay with nine microsatellite markers spanning from 3 p14.2 to 3 pter. Of the 36 OSCCs that were informative for at least two of the loci, $26(72 \%)$ showed LOH, while in OEDLs, LOH was detected in $18 \%(5 / 28)$. Figure 1 shows representative cases with typical $\mathrm{LOH}$ and $\mathrm{MI}$ results. The results of the PCR-LOH assay are summarized in Table 2. Frequencies for individual marker loci in OSCC ranged from $23 \%$ to $61 \%$, with a maximum at $\operatorname{D} 3 \mathrm{~S} 2450(61 \%)$, at which no allelic deletion was detected in OEDL. Comparing the frequency of LOH in OSCC and OEDL, LOH frequency in OEDL was apparently lower at each locus than that in OSCC. The loci D3S2450, D3S1514, D3S2420, and D3S1540 had no LOH in OEDL.

Frequency of microsatellite instability on chromosome $3 p$

Except for one OSCC sample that had MI at two loci, most OSCCs had no band shift on gel electrophoresis (Fig. 1). Three OEDLs showed evidence of MI. Of these, one showed MI at two loci, and two showed MI at one locus. In total, only four (6\%) of the 64 samples of OSCC and OEDL showed MI (Table 2). It was suggested that mismatch-repair genes are not usually involved in carcinogenesis in OSCC.

Table 2. Cumulative results of LOH and MI on chromosome $3 p$ in 36 OSCCs and 28 OEDLs

\begin{tabular}{|c|c|c|c|c|c|c|}
\hline \multirow[b]{2}{*}{$\begin{array}{l}\text { Locus symbol } \\
\text { (chromosome location) }\end{array}$} & \multicolumn{3}{|l|}{ OSCC } & \multicolumn{3}{|l|}{ OEDL } \\
\hline & $\begin{array}{l}\text { Informative } \\
\text { cases }(\%)\end{array}$ & $\begin{array}{l}\text { Frequency } \\
\text { of LOH }(\%)\end{array}$ & $\begin{array}{l}\text { MI } \\
\text { cases }\end{array}$ & $\begin{array}{l}\text { Informative } \\
\text { cases }(\%)\end{array}$ & $\begin{array}{l}\text { Frequency } \\
\text { of LOH }(\%)\end{array}$ & $\begin{array}{l}\text { MI } \\
\text { cases }\end{array}$ \\
\hline D3S2450 (3pter-p24.2) & $21(58 \%)$ & $14(61 \%)$ & 0 & $10(36 \%)$ & $0(0 \%)$ & 0 \\
\hline D3S151 (3p25-p24.2) & $23(64 \%)$ & $12(52 \%)$ & 0 & $13(46 \%)$ & $2(15 \%)$ & 0 \\
\hline D3S1537 (3p24.2-p22) & $28(78 \%)$ & $9(32 \%)$ & 0 & $16(57 \%)$ & $2(13 \%)$ & 2 \\
\hline D3S2447 (3p24.2-p22) & $25(69 \%)$ & $9(36 \%)$ & 1 & $19(68 \%)$ & $1(5 \%)$ & 0 \\
\hline D3S2414 (3p24.2-p22) & $21(58 \%)$ & $5(23 \%)$ & 0 & $12(43 \%)$ & $1(8 \%)$ & 0 \\
\hline D3S2411 (3p24.2-p22) & $12(33 \%)$ & $6(50 \%)$ & 0 & $6(21 \%)$ & $1(17 \%)$ & 1 \\
\hline D3S2420 (3p21.3-p21.2) & $26(72 \%)$ & $8(30 \%)$ & 0 & $18(64 \%)$ & $0(0 \%)$ & 1 \\
\hline D3S1514 (3p21.1-p14.2) & $27(75 \%)$ & $10(37 \%)$ & 0 & $21(75 \%)$ & $0(0 \%)$ & 0 \\
\hline D3S1540 (3p21.1-p14.2) & $24(67 \%)$ & $10(41 \%)$ & 1 & $19(68 \%)$ & $0(0 \%)$ & 0 \\
\hline
\end{tabular}

LOH, Loss of heterozygosity; MI, microsatellite instability 
Relationship between LOH on chromosome $3 p$ and clinicopathological factors

We investigated the correlation between clinicopathological factors and $\mathrm{LOH}$ on chromosome $3 \mathrm{p}$. An interesting result was obtained at D3S2450 (3pter-p.24.2), in which LOH was most frequently observed (Table 3). Ten of the 14 OSCCs with LOH were the highly invasive type (grade 3, 4C, 4D), while 6 of the 7 without $\mathrm{LOH}$ were the low invasive type (grade 1,2). There was a significant association between LOH of D3S2450 and mode of tumor invasion $(P<0.05)$. Furthermore, lymph node metastasis was not observed in OSCC without $\mathrm{LOH}$ at this locus. Although the relation between $\mathrm{LOH}$ of $\mathrm{D} 3 \mathrm{~S} 2450$ and lymph node

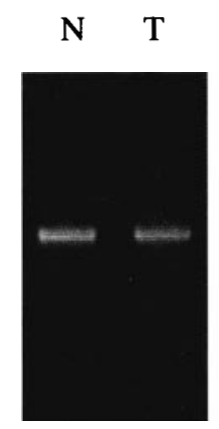

$\mathbf{a}$

Not informative

D3S2450

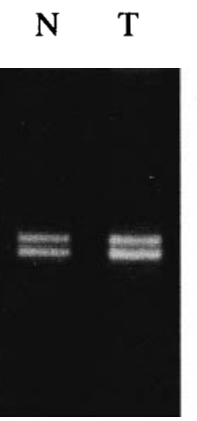

b

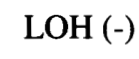

D3S2447

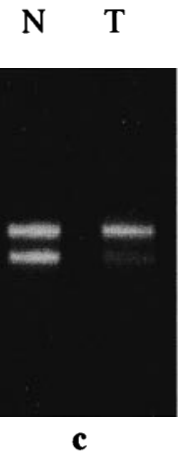

$\mathrm{LOH}(+)$

D3S2447
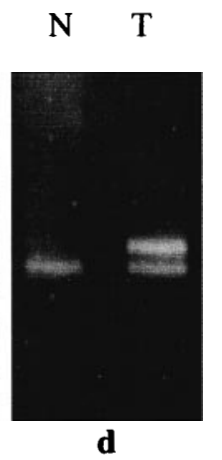

MI

D3S1514
Fig. 1a-d. Representative patterns of a not informative, $\mathbf{b}$ retention of both alleles (loss of heterozygosity; $\mathrm{LOH}(-))$, c allelic deletion $(\mathrm{LOH}$ $(+))$, and $\mathbf{d}$ microsatellite instability $(M I)$ on chromosome $3 \mathrm{p} . N$, Normal DNA; $T$, tumor DNA

metastasis did not reach statistical significance, because of the small sample size, detection of $\mathrm{LOH}$ at the D3S2450 locus may be indicative of progressive disease with lymph node metastasis. For other markers, we failed to demonstrate any relationship between $\mathrm{LOH}$ and clinicopathological factors, in terms of differentiation grade, lymph node metastasis, and mode of tumor invasion.

Common deletion region at 3p25-p26

We observed the maximum LOH at locus D3S2450, which is located at 3pter-p24.2. To find a common deletion region at 3pter-p24.2, we examined normal and tumor DNA from the 36 OSCCs for allelic deletions at eight microsatellite markers located in 3pter-p24.2, including D3SD2450, by fluorescent microsatellite assay. Figure 2 shows the pattern of $\mathrm{LOH}$ and MI. Frequencies for individual marker loci in OSCC ranged from $24 \%$ to $61 \%$, with a maximum at D3S2450 (Fig. 3). At D3S1304, sited telomeric to D3S2450,

Table 3. Relationship between LOH of D3S2450 (3pter-p24.2) and clinicopathological features in OSCC

\begin{tabular}{lrlll}
\hline & \multicolumn{2}{l}{ LOH of D3S2450 } & \\
\cline { 2 - 4 } Characteristics & $(+)$ & $(-)$ & Percentage & $P$ value \\
\hline $\begin{array}{l}\text { Differentiation } \\
\quad \text { Well }\end{array}$ & 5 & 5 & 50 & \\
$\quad \begin{array}{l}\text { Moderate, poor } \\
\text { Mode of tumor invasion }\end{array}$ & 9 & 2 & 82 & 0.27 \\
$\quad$ Grades 1, 2 & 4 & 6 & 40 & \\
$\quad$ Grades 3, 4C, 4D & 10 & 1 & 91 & $<0.05$ \\
$\begin{array}{l}\text { Lymph node metastasis } \\
(+)\end{array}$ & 5 & 0 & 100 & \\
$(-)$ & 9 & 7 & 56 & 0.20 \\
\hline
\end{tabular}

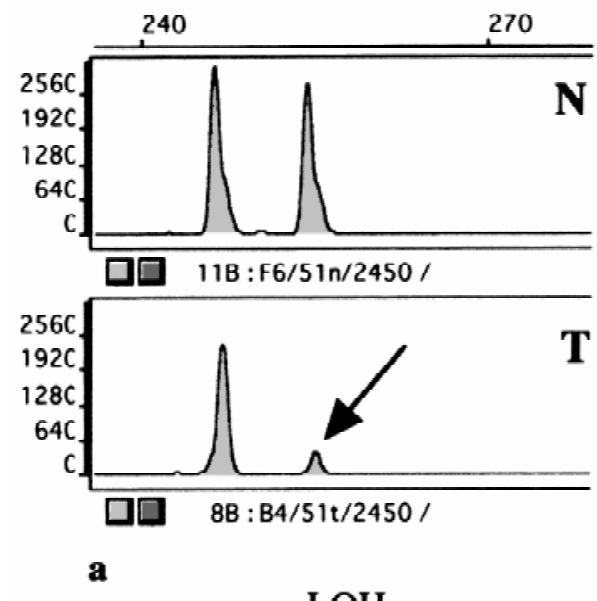

$\mathrm{LOH}$ at D3S2450

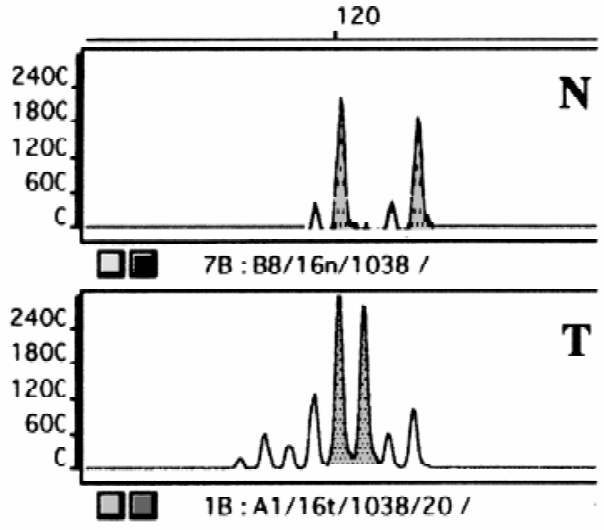

b

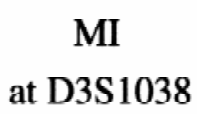

Fig. 2. Loss of heterozygosity ( $\mathrm{LOH}$ ) of D3S2450 and microsatellite instability (MI) of D3S1038 in oral squamous cell carcinoma (OSCC) detected by fluorescent polymerase chain reaction (PCR). Data were obtained with the ABI PRISM 310 Genetic Analyzer. The $\mathrm{X}$ axis shows fragment size in bp. $T$, DNA from tumor; $N$, DNA from peripheral blood. a A heterozygous individual (246bp, $254 \mathrm{bp}$ ) is shown for each normal/tumor DNA. Arrow shows deletion of a longer allele in tumor DNA. An LOH value of 0.20 clearly indicates $\mathrm{LOH}$ in the tumor sample. b In the normal sample, the shorter allele is $120 \mathrm{bp}$ and the longer allele is $126 \mathrm{bp}$. In the tumor sample, the longer allele is shifted to $122 \mathrm{bp}$, indicating MI 


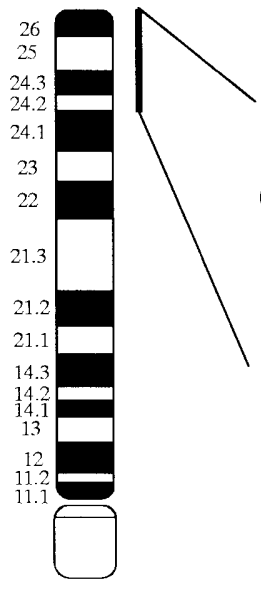

Fig. 3. Deletion mapping of chromosome $3 p$ terminal in oral squamous cell carcinomas. Closed circles, Loss of heterozygosity; open circles, retention of both alleles; dashes, not informative; stars, microsatellite instability. Although the region bordered by D3S1304 and D3S2450

11 of 31 informative cases $(35 \%)$ showed LOH, whereas 12 of 23 informative cases $(52 \%)$ showed LOH at D3S3591, sited centromeric to D3S2450. In case 22, LOH at D3S3591 and retention of heterozygosity at flanking markers D3S1304 and D3S1038 were clearly seen. In addition, cases 3 and 5, which have a typical interstitial deletion, showed $\mathrm{LOH}$ at D3S3591 and retention at D3S2450, indicating that a telomeric breakpoint of the common deletion region is between D3D3591 and D3S2450. Conversely, LOH at D3S2450 and retention at D3S3591 were seen in cases 7 and 21 , indicating that a centromeric breakpoint is between these two markers. An interstitial deletion between D3S2450 and D3S3591 was strongly suggested in OSCC, and, accordingly, we found a common deletion region within a $0.8-\mathrm{cM}$ region containing D3S2450 and D3S3591 in 3p25-p26. Next, using LOH analysis of D3S2450 and D3S3591, we tested whether the common deletion region was associated with any clinical features of OSCC. Twenty (65\%) of 31 informative cases showed LOH at D3S2450 and D3S3591. No strong correlation was found among allelic deletions with respect to differentiation grade, tumor size, lymph node metastasis, and stage. However, a significant correlation between LOH and mode of tumor invasion was observed (Table 4). These results provide evidence for the presence of a tumor suppressor gene in a $0.8-\mathrm{cM}$ region bordered by D3S2450 and D3S3591 at 3p25-p26, which may play a role in carcinogenesis and invasion of OSCC. On comparing groups with and without lymph node metastasis we found that $8(40 \%)$ of 20 patients in the LOH-positive group had lymph node metastasis, versus only $2(18 \%)$ of 11 in the LOH-negative group. Although there was no significant association, $\mathrm{LOH}$ detection in this common deletion region may be a useful tool for the prediction of lymph node metastasis prior to treatment. In the analysis of the $3 p$ terminal by fluorescent microsatellite assay, only three (cases 15,22 , and 24) showed MI, and a low frequency of MI was revealed in OSCC, as had been shown in a previous preliminary assessment. common deletion region

was 0 -cM by our linkage analysis, the distance was $50 \mathrm{kbp}$ according to the database of sequence tagged sites of the National Center for Biotechnology Information. We found a common deletion region within a $0.8-\mathrm{cM}$ region bordered by D3S2450 and D3S3591 at 3p25-p26

Table 4. Relationship between $\mathrm{LOH}$ of common deletion region (3p25-p26) and clinicopathological features in OSCC

\begin{tabular}{|c|c|c|c|}
\hline \multirow[b]{2}{*}{ Characteristics } & \multicolumn{2}{|c|}{$\begin{array}{l}\text { LOH of common } \\
\text { deleted region }\end{array}$} & \multirow[b]{2}{*}{$P$ value } \\
\hline & $\mathrm{LOH}(+)$ & $\mathrm{LOH}(-)$ & \\
\hline \multicolumn{4}{|l|}{ Differentiation } \\
\hline Well & 8 & 7 & \\
\hline Moderate, poor & 12 & 4 & 0.19 \\
\hline \multicolumn{4}{|c|}{ Mode of tumor invasion } \\
\hline Grades 1,2 & 5 & 10 & \\
\hline Grades 3, 4C, 4D & 15 & 1 & $<0.001$ \\
\hline \multicolumn{4}{|l|}{ Tumor size } \\
\hline 1,2 & 12 & 10 & \\
\hline 3,4 & 8 & 1 & 0.08 \\
\hline \multicolumn{4}{|c|}{ Lymph node metastasis } \\
\hline$(+)$ & 8 & 2 & \\
\hline \multirow[t]{2}{*}{$(-)$} & 12 & 9 & 0.20 \\
\hline & $40 \%$ & $18 \%$ & \\
\hline \multicolumn{4}{|l|}{ TNM stage } \\
\hline I, II & 8 & 8 & \\
\hline III, IV & 12 & 3 & 0.08 \\
\hline
\end{tabular}

\section{Discussion}

To evaluate the role of $3 p$ deletions in the pathogenesis of OSCC, we studied 36 OSCCs for LOH, using microsatellite markers at 3pter-p14.2. LOH was observed in $72 \%$ of the OSCCs, and a common deletion region, at 3p25-p26, was identified. The common deletion region is consistent with that reported for renal cell carcinoma by Alimov et al. (2000), who evaluated deletions on $3 p$ by LOH and comparative genome hybridization (CGH) analysis; the common deletion region is also consistent with that reported for OSCC by Uzawa et al. (1998), who analyzed DNA of the fragments derived from transferred $3 p$ in microcell hybrid clones. Our present data provide evidence for the presence of a tumor suppressor gene at 3p25-p26 in OSCC. The gene 
responsible for von Hippel-Lindau (VHL) disease was isolated from $3 \mathrm{p} 25$. VHL disease is a dominantly inherited familial cancer syndrome that predisposes affected individuals to a variety of tumors, in particular, hemangioblastoma of the central nervous system and retina, renal cell carcinoma, and pheochromocytoma. The VHL gene lies within $10 \mathrm{cM}$ between D3S1597 and D3S1293, which is centromeric above $2.9-\mathrm{cM}$ from the common deletion region that we found. $\mathrm{LOH}$ frequencies at D3S1597 and D3S1293 were $24 \%$ and $34 \%$, respectively, with lower frequencies than those of the common deletion region. It was also reported that mutation of the VHL gene was not found in OSCC by PCR-single strand conformation polymorphism (SSCP) analysis (Uzawa et al. 1995). Our results may also provide evidence for the presence of a tumor suppressor gene, other than the $V H L$ gene, that may play a role in carcinogenesis and invasion of OSCC. Moreover, $\mathrm{LOH}$ at D3S2411 in OSCC showed a relatively high incidence $(50 \%)$ in the preliminary assessment, although the frequency of informative cases was low $(33 \%)$. The transforming growth factor (TGF)-beta type 2 receptor has been mapped approximately 5-cM centromeric to D3S2411 at 3p22. It has been suggested that alterations in the nucleic acid sequence and mRNA expression of TGF-beta type 2 receptor are prevalent events in the development of head and neck cancer, which may deregulate cell cycle control (Wang et al. 1997). It is possible that TGF-beta type 2 receptor contributes to the suppression of tumorigenesis in OSCC.

To determine whether $\mathrm{LOH}$ on chromosome $3 p$ occurs as an early event or as a late event in OSCC tumorigenesis, we investigated LOH on $3 p$ in 28 OEDLs, as well as in OSCCs. Regarding this, there is still controversy in the literature: El-Naggar et al. (1995) suggested that LOH at 3p was a late event, because they found $\mathrm{LOH}$ in only $5 \%(1 / 20)$ of oral dysplastic lesions, while Roz et al. (1996) provided evidence that LOH may be an early event in OSCC tumorigenesis. Most recently, Rosin et al. (2000) examined LOH to compare progressive and nonprogressive low-grade oral epithelial dysplasias. They reported that $3 p$ and $9 p$ losses were increased in lesions that later progressed to cancer, and they found a significant difference between lesions with and without progression. Hence, as all of our OEDL samples showed no progression during follow-up, we considered that the LOH frequency in OEDL was low. We found no LOH at 3p21.3-p14.2 and 3p terminal in OEDL samples. Taking all these results together, we assume that there may be a common deletion region between D3S2450 and D3S3591 at 3p25-26, at most 0.8-cM long, telomeric to the $V H L$ gene locus.

As mentioned in the Introduction, the findings with relation to clinicopathological factors are provocative, because a tumor suppressor gene can be expected at that locus. To our knowledge, in head and neck cancer: (a) LOH of 9p21p23 is related to advanced local invasion, lymph node metastasis, and stage IV tumor (Jares et al. 1997); (b) LOH of 9p21 and 7q31 is related to a high incidence of recurrent tumor (Matsuura et al. 1998); (c) LOH of 18q is related to survival (Pearlstein et al. 1998); (d) LOH of 2q is related to poor prognosis (Ransom et al. 1998); (e) LOH of 13q14.3 is related to lymph node metastasis (Ogawara et al. 1998); and (f) $\mathrm{LOH}$ of $11 \mathrm{q} 23$ is related to recurrence (Lazar et al. 1998). In this study, we found a locus exhibiting a high rate of $\mathrm{LOH}$ at 3p25-p26, which was associated with the mode of tumor invasion. Elucidation of allelic deletions in human cancers is regarded as important for the understanding and treatment of tumors. Therefore, in OSCC, assessment of $\mathrm{LOH}$ at the aforementioned 2q, 3p, 7q, 9p, 11q, 13q, and $18 \mathrm{q}$ loci promises to be valuable in improving the survival rate.

MI comprises length mutations in tandem oligonucleotide repeats. This type of mutation is believed to be caused by altered DNA mismatch-repair genes. Recent literature suggests that $h M L H 1$ promoter hypermethylation is associated with $h M L H 1$ transcriptional inactivation and mismatch-repair deficiency in a large proportion of MIpositive gastric carcinomas (Fleisher et al. 1999). However, in oral cancer, our findings suggest that mismatch-repair genes are not usually involved in carcinogenesis, because, in our 64 samples, MI-positive samples were relatively few $(6 \%)$.

In conclusion, we used microsatellite polymorphism analysis to screen LOH frequency of $3 p$ in OSCC and OEDL, and identified a common deletion region (3p25p26), where a tumor suppressor gene associated with invasive OSCC may be located. We are currently investigating the target genes at $3 \mathrm{p} 25-26$, using bacterial artificial chromosome (BAC) contig and subsequent complete genome sequencing.

Acknowledgments This work was supported in part by a Grant in Aid 12771225 for Encouragement of Young Scientists from the Ministry of Education, Science, Sports, and Culture of Japan.

\section{References}

Alimov A, Kost-Alimova M, Liu J, Li C, Bergerheim U, Imreh S, Klein G, Zabarovsky ER (2000) Combined LOH/CGH analysis proves the existence of interstitial $3 p$ deletions in renal cell carcinoma. Oncogene 19:1392-1399

Califano J, Leong PL, Koch WM, Eisenberger CF, Sidransky D, Westra WH (1999) Second esophageal tumors in patients with head and neck squamous cell carcinoma: an assessment of clonal relationships. Clin Cancer Res 5:1862-1867

Cawkwell L, Lewis FA, Quirke P (1994) Frequency of allele loss of DCC, p53, RBI, WT1, NF1, NM23 and APC/MCC in colorectal cancer assayed by fluorescent multiplex polymerase chain reaction. Br J Cancer 70:813-818

Chino K, Esumi M, Ishida H, Okada K (1999) Characteristic loss of heterozygosity in chromosome $3 \mathrm{P}$ and low frequency of replication errors in sporadic renal cell carcinoma. J Urol 162:614-618

El-Naggar AK, Hurr K, Batsakis JG, Luna MA, Goepfert H, Huff V (1995) Sequential loss of heterozygosity at microsatellite motifs in preinvasive and invasive head and neck squamous carcinoma. Cancer Res 55:2656-2659

El-Naggar AK, Coombes MM, Batsakis JG, Hong WK, Goepfert H, Kagan J (1998) Localization of chromosome 8p regions involved in early tumorigenesis of oral and laryngeal squamous carcinoma. Oncogene 16:2983-2987

Fleisher AS, Esteller M, Wang S, Tamura G, Suzuki H, Yin J, Zou TT, Abraham JM, Kong D, Smolinski KN, Shi YQ, Rhyu MG, Powell SM, James SP, Wilson KT, Herman JG, Meltzer SJ (1999) 
Hypermethylation of the hMLH1 gene promoter in human gastric cancers with microsatellite instability. Cancer Res 59:1090-1095

Fullwood P, Marchini S, Rader JS, Martinez A, Macartney D, Broggini M, Morelli C, Barbanti-Brodano G, Maher ER, Latif F (1999) Detailed genetic and physical mapping of tumor suppressor loci on chromosome $3 p$ in ovarian cancer. Cancer Res 59:4662-4667

Gasparotto D, Vukosavljevic T, Piccinin S, Barzan L, Sulfaro S, Armellin M, Boiocchi M, Maestro R (1999) Loss of heterozygosity at $10 \mathrm{q}$ in tumors of the upper respiratory tract is associated with poor prognosis. Int J Cancer 84:432-436

Ishwad CS, Ferrell RE, Rossie KN, Appel BN, Johnson JT, Myers EN, Law JC, Srivastava S, Gollin SM (1996) Loss of heterozygosity of the short arm of chromosomes 3 and 9 in oral cancer. Int $\mathrm{J}$ Cancer 69:1-4

Jares P, Fernandez PL, Nadal A, Cazorla M, Hernandez L, Pinyol M, Hernandez S, Traserra J, Casdesa A, Campo E (1997) p16MTS1/ CDK4I mutations and concomitant loss of heterozygosity at 9p21-23 are frequent events in squamous cell carcinoma of the larynx. Oncogene 15:1445-1453

Lazar AD, Winter MR, Nogueira CP, Larson PS, Finnemore EM, Dolan RW, Fuleihan N, Chakravarti A, Zietman A, Rosenberg CL (1998) Loss of heterozygosity at 11q23 in squamous cell carcinoma of the head and neck is associated with recurrent disease. Clin Cancer Res 4:2787-2793

Matsuura K, Shiga K, Yokoyama J, Saijo S, Miyagi T, Takasaka T (1998) Loss of heterozygosity of chromosome 9p21 and 7q31 is correlated with high incidence of recurrent tumor in head and neck squamous cell carcinoma. Anticancer Res 18:453-458

Mitsudomi T, Oyama T, Nishida K, Ogami A, Osaki T, Sugio K, Yasumoto K, Sugimachi K, Gazdar AF (1996) Loss of heterozygosity at $3 p$ in non-small cell lung cancer and its prognostic implication. Clin Cancer Res 2:1185-1189

Miyakawa A, Wang XL, Nakanishi H, Imai FL, Shiiba M, Miya T, Imai Y, Tanzawa H (1998) Allelic loss on chromosome 22 in oral cancer: possibility of the existence of a tumor suppressor gene on 22q13. Int J Oncol 13:705-709

Mutirangura A, Pornthanakasem W, Sriuranpong V, Supiyaphun P, Voravud N (1998) Loss of heterozygosity on chromosome 14 in nasopharyngeal carcinoma. Int J Cancer 78:153-156

Ogawara K, Miyakawa A, Shiba M, Uzawa K, Watanabe T, Wang XL, Sato T, Kubosawa H, Kondo Y, Tanzawa H (1998) Allelic loss of chromosome 13q14.3 in human oral cancer: correlation with lymph node metastasis. Int J Cancer 79:312-317

Partridge M, Kiguwa S, Langdon JD (1994) Frequent deletion of chromosome $3 p$ in oral squamous cell carcinoma. Eur J Cancer B Oral Oncol 30B: 248-251
Partridge M, Emilion G, Langdon JD (1996) LOH at 3p correlates with a poor survival in oral squamous cell carcinoma. Br J Cancer 73:366371

Pearlstein RP, Benninger MS, Carey TE, Zarbo RJ, Torres FX, Rybicki BA, Dyke DL (1998) Loss of 18q predicts poor survival of patients with squamous cell carcinoma of the head and neck. Genes Chromosomes Cancer 21:333-339

Ponder B (1988) Cancer. Gene losses in human tumours. Nature 335:400-402

Ransom DT, Barnett TC, Bot J, de Boer B, Metcalf C, Davidson JA, Turbett GR (1998) Loss of heterozygosity on chromosome 2q: possibly a poor prognostic factor in head and neck cancer. Head Neck 20:404-410

Rosin MP, Cheng X, Poh C, Lam WL, Huang Y, Lovas J, Berean K, Epstein JB, Priddy R, Le ND, Zhang L (2000) Use of allelic loss to predict malignant risk for low-grade oral epithelial dysplasia. Clin Cancer Res 6:357-362

Roz L, Wu CL, Porter S, Scully C, Speight P, Read A, Sloan P, Thakker N (1996) Allelic imbalance on chromosome 3p in oral dysplastic lesions: an early event in oral carcinogenesis. Cancer Res 56:12281231

Schmitt FC, Soares R, Gobbi H, Milanezzi F, Santos-Silva F, Cirnes L, Costa C, Seruca R (1999) Microsatellite instability in medullary breast carcinomas. Int J Cancer 82:644-647

Uzawa K, Suzuki H, Yokoe H, Tanzawa H, Sato K (1995) Mutational state of p16/CDKN2 and VHL genes in squamous-cell carcinoma of the oral cavity. Int J Oncol 7:895-899

Uzawa K, Suzuki H, Komiya A, Nakanishi, H, Ogawara K, Tanzawa H, Sato K (1996) Evidence for two distinct tumor-suppressor gene loci on the long arm of chromosome 11 in human oral cancer. Int $\mathbf{J}$ Cancer 67:510-514

Uzawa N, Yoshida MA, Hosoe S, Oshimura M, Amagasa T, Ikeuchi T (1998) Functional evidence for involvement of multiple putative tumor suppressor genes on the short arm of chromosome 3 in human oral squamous cell carcinogenesis. Cancer Genet Cytogenet 107:125-131

Wang D, Song H, Evans JA, Lang JC, Schuller DE, Weghorst CM (1997) Mutation and downregulation of the transforming growth factor beta type II receptor gene in primary squamous cell carcinomas of the head and neck. Carcinogenesis 18:2285-2290

Wang XL, Uzawa K, Imai FL, Tanzawa H (1999) Localization of a novel tumor suppressor gene associated with human oral cancer on chromosome 4q25. Oncogene 18:823-825

Yamamoto E, Kohama G, Sunakawa H, Iwai M, Hiratsuka H (1983) Mode of invasion, bleomycin sensitivity, and clinical course in squamous cell carcinoma of the oral cavity. Cancer 51:2175-2180 